\title{
NEUROBEHAVIOURAL FUNCTIONS IN ADULT PROGENY OF RAT MOTHERS EXPOSED TO METHYLMERCURY OR 2,2',4,4',5,5'-HEXACHLOROBIPHENYL (PCB 153) ALONE OR THEIR COMBINATION DURING GESTATION AND LACTATION
}

\section{SŁAWOMIR GRALEWICZ, DOROTA WIADERNA, PIOTR LUTZ, and KRYSTYNA SITAREK}

Nofer Institute of Occupational Medicine, Łódź, Poland

Department of Toxicology and Carcinogenesis

\begin{abstract}
Objectives: Methylmercury (MeHg) and polychlorinated biphenyls (PCBs) are ubiquitous environmental pollutants. Both are neurotoxic, especially for the developing brain. The main source of human exposure to $\mathrm{MeHg}$ and PCBs is seafood. The aim of the present work was to find out whether and how separate or combined perinatal exposure to these neurotoxicants affects neurobehavioural functions in maturity. Materials and Methods: The study was performed on adult Wistar rats, the progeny of rat mothers exposed to MeHg $(0.5 \mathrm{mg} / \mathrm{kg} /$ day or $2.0 \mathrm{mg} / \mathrm{kg} / \mathrm{day})$, PCB $153(1.0 \mathrm{mg} / \mathrm{kg} / \mathrm{day}$ or $5.0 \mathrm{mg} / \mathrm{kg} /$ day), or to $\mathrm{MeHg} 0.5 \mathrm{mg} / \mathrm{kg} /$ day + PCB $1535.0 \mathrm{mg} / \mathrm{kg} /$ day, from day 7 of pregnancy to day 21 post partum. The following functions were assessed: spontaneous locomotor activity (open field test), spatial short-term memory (radial maze test), long-term memory (passive avoidance test), sensitivity to pain and vulnerability to stress (hot plate test), efficiency of the sensorimotor gating (startle response test), and sensorimotor coordination (the rotarod test). Results: The results obtained in the $\mathrm{MeHg}$ part of the study showed a reduced locomotor activity in the female progeny of both exposed groups, an impaired passive avoidance in the male progeny of the high and low exposure group and a faster recovery from the effects of the stressful experience (hot plate test) in the male progeny of the high dose group. Results obtained in the PCB part showed an increased locomotor activity in the female progeny of both exposure groups and impairment in rotarod performance in males of the high dose group. Neurobehavioural alterations were not found in either the females or males exposed jointly to MeHg and PCB 153. Conclusions: The results suggest that in condition of the combined exposure, $\mathrm{MeHg}$ may protect against the effects of PCB 153 and vice versa.
\end{abstract}

Key words:

MeHg, PCB 153, Perinatal exposure, Behaviour, Rat

\section{INTRODUCTION}

The contamination of food products by toxic chemicals is one of the main issues of concern for agencies dealing with the problem of chemical safety. Methylmercury (MeHg) and polychlorinated biphenyls (PCBs) are common environmental pollutants. Both may be present in some foods, especially in sea fish and frutti di mare.
Both are neurotoxic and cross biological barriers easily. The vulnerability of the nervous system to toxic insults is the highest during intrauterine life [1], which means that consumption of $\mathrm{MeHg}$ and/or PCB contaminated food during pregnancy may endanger the child psychophysical development. The possibility of co-presence of $\mathrm{MeHg}$ and PCBs in diet raises the question of the type of

Received: March 31, 2009. Accepted: May 21, 2009

Address reprint request to S. Gralewicz, Department of Toxicology and Carcinogenesis, Nofer Institute of Occupational Medicine, św. Teresy 8 St., 91-348 Łódź, Poland (e-mail: gralslaw@imp.lodz.pl). 
interaction between these two contaminants. Results of some in vitro studies suggest that, at some concentration combinations of $\mathrm{MeHg}$ and $\mathrm{PCB}$, the effects are more than additive $[2,3]$. Such interaction could explain the inconsistencies between the results of the epidemiological studies on large children cohorts from two islander populations with very high contribution of seafood in diet: the Faeroe and the Seychelles cohorts. Whereas the studies of the Faeroe cohort suggest detrimental effect of maternal diet on some neurobehavioural functions [4-6], in the Seychelles cohort such effects were not observed [7-9]. Based on the in vitro observations quoted above, some authors presume that the differences between the Seychelles and Faroe Island studies could be a consequence of the co-presence of PCBs and $\mathrm{MeHg}$ in the diet of the Faroe group [10,11]. Experimental in vivo studies performed so far provided no definitive confirmation or negation of this supposition $[12,13]$.

The experiments described in the present paper are a part of a larger study, performed as part of the DEVNERTOX project sponsored by the EU Commission (DEVNERTOX, Contract No. 6PR/03/506143). One of the main objectives of this project was establishing how, if at all, $\mathrm{MeHg}$ and selected PCB congeners interact in affecting neurodevelopment. The study was composed of three experiments as described before [14]. The purpose of the present part was to determine the neurobehavioural status of the adult progeny of rat mothers exposed, during gestation and lactation, to $\mathrm{MeHg}$ and a PCB congener, both alone and in combination. The PCB congener selected for the study was PCB 153 (2,2',4,4',5,5'-hexachlorobiphenyl). PCB 153 is the congener which is found most frequently in biological samples, including human tissues [15].

\section{MATERIALS AND METHODS}

\section{Study design}

The study agenda and the design of the experiments have been presented in details in our recent reports [14,16,17]. In short, the study comprised three separate experiments. Experiment I concerned the effects of perinatal exposure to $\mathrm{MeHg}$, Experiment II - the effects of exposure to PCB 153, and Experiment III, the effects of combined exposure to $\mathrm{MeHg}$ and PCB 153. Each of the experiments comprised four parts. The purpose of part one was to find out the early - from birth to weaning - developmental effects of the exposure. After weaning, the progeny was allowed to grow and served as the material for the remaining parts, of which the second was concerned with the effect of exposure on the brain concentration of catecholamines, the third with behavioural sensitivity to the psychostimulant amphetamine (AMPH), and the fourth with the neurobehavioural functions. The present report contains results of the fourth part dealing with the neurobehavioural functions in adulthood.

\section{Animals}

White WISTAR rats of the outbreed Imp: Wist stock were used in the experiments. The housing conditions, the mating procedure and the conception control have been described in detail in the accompanying paper [14]. In all the experiments, the Polish law on the protection of animals was observed (Animal Protection Act of August 21, 1997. Off. J. Law 1997;111:3445-53, in Polish). The study design was approved by the Local Ethics Committee in Łódź (Opinion No: Ł/BD/187, Issue date: 2003-12-1).

\section{Exposure and exposure control}

The exposures were carried out from gestation day 7 (GD7) until the postnatal day 21 (PND 21). $\mathrm{MeHg}$ $\left(\mathrm{CH}_{3} \mathrm{HgCl}\right.$, CAS No. 115-09-3 from Sigma-Aldrich) was administered with the drinking water. PCB 153 (2,2',4,4',5,5'-hexachlorobiphenyl, CAS No. 35065-27-1 from Fluka) was diluted with corn oil to the required concentration and administered intragastrically by gavage. Details of the exposure procedure have been presented in the report concerning the effects of exposure during the preweaning period of life [14]. In Experiment I (exposure to $\mathrm{MeHg}$ ), the expected daily $\mathrm{MeHg}$ intake was $0.5 \mathrm{mg} / \mathrm{kg} / \mathrm{day}$ in the low exposure group and $2.0 \mathrm{mg} / \mathrm{kg} / \mathrm{day}$ in the high dose group. Mothers of the control group received water not adulterated with MeHg. In Experiment II (exposure to PCB), PCB 153 
was administered intragastrically by gavage at $1.0 \mathrm{mg} / \mathrm{kg}$ in the low exposure group and $5.0 \mathrm{mg} / \mathrm{kg}$ in the high dose group. Mothers of the control group received pure corn oil via the same route. In Experiment III (combined exposure), mothers of the exposed group received $0.5 \mathrm{mg} / \mathrm{kg} /$ day of $\mathrm{MeHg}$ and $5.0 \mathrm{mg} / \mathrm{kg} /$ day of PCB 153. Mothers of the control group drank water not adulterated with $\mathrm{MeHg}$ and received pure corn oil.

\section{Assessment of the offspring before weaning}

From birth (PND 1) to weaning (PND 21) the offspring was assessed for the general appearance, litter weight, mean pup weight (for males and females separately) and mortality. Additionally, the following developmental milestones were recorded: pinna detachment, incisor eruption, and eye opening. Assessed were also: negative geotaxis, grip strength (the forepaw suspension test), and the righting reflex (the free-fall righting test). Details of the procedures have been presented already [14].

\section{Postweaning procedures}

Pups were weaned at PND21. They were separated into exposure/gender groups and allocated into group cages (up to 4 animals per cage matched for gender and treatment) where they remained for about eight weeks. During this time they were not disturbed, except for the routine weekly weighing and bedding changing. At 75-80 days of age the animals were allocated to single rat cages. Each exposure/gender group was divided into three parts (see the study design). Care was taken to assure that each part contained members of each litter.

\section{Neurobehavioural assessment}

\section{and the neurobehavioural tests battery}

The test battery consisted of the following tests: open-field test (assessment of motoric behaviour), radial maze test (assessment of spatial working memory), passive avoidance test (assessment of long-term memory), hot-plate test (assessment of pain sensitivity and the magnitude of the stress-induced analgesia), and startle response and startle prepulse inhibition (assessment of auditory function and sensorimotor gating). In the experiments concerning the exposure to PCB 153 alone and joint exposure to $\mathrm{MeHg}$ and PCB 153 , the test battery was supplemented with testing on rotarod (rotarod test) in order to assess the sensorimotor coordination. The succession of testing was as follows:

Table 1. Tests and testing succession

\begin{tabular}{lc}
\hline \multicolumn{1}{c}{ Test } & Rat's age (weeks) \\
\hline Open field & 13 \\
Radial maze & $14-15$ \\
Passive avoidance & $16-17$ \\
Hot-plate & 18 \\
Startle response & 19 \\
Rotarod & 20 \\
\hline
\end{tabular}

Open field test

A computerised 4-unit set of activity cages (PORFEXLtd., Białystok, Poland) was used. Each cage $(63 \times 63 \times 40 \mathrm{~cm})$ was equipped with 2 tiers of infrared motion sensors to measure locomotor (travelled distance) and exploratory (rearings) activities. Detailed description of the apparatus and the testing procedure have been presented in other reports [16,18]. For testing the spontaneous behaviour, the rat was placed in the activity cage once for $60 \mathrm{~min}$.

\section{Radial maze test}

The 8-arm radial maze used in the present study, the experimental settings and the test procedure were described in detail earlier [19]. In short, water was used as the reward. The testing run comprised 2 stages: adaptation and training. The adaptation consisted of 3 trials (one trial per day). During each adaptation trial the containers $\left(0.5 \mathrm{~cm}^{3}\right)$ at the end of each arm were filled with water and the rat was allowed to explore the maze for $3 \mathrm{~min}$. The training stage consisted of 5 trials (one trial/day). Before each training trial the rats were water-deprived for about $23.5 \mathrm{~h}$. The trial ended after eight choices were made or 3 min elapsed. The following data were collected during each stage: the number of arms omitted (omission errors), the number of re-entries (perseveration errors), and the time required to complete the trial (trial duration). 
Passive avoidance test

The passive avoidance situation (step-down type) and the test procedure were described in detail previously [19]. The test consisted of 2 preshock trials (trials 1 and 2), 1 shock trial (trial 3 ) and 3 postshock trials (trials 4, 5 and 6). Trials 1, 2 and 3 were performed at $24 \mathrm{~h}$ intervals, Trials 4, 5 and 6 were performed $24 \mathrm{~h}, 3$ and 7 days, respectively, after trial 3 . In preshock trials the rat was placed on the platform and, after stepping down, it was allowed to explore the cage for $1 \mathrm{~min}$. In the shock trial, the rat received a $10 \mathrm{~s}$ series of scrambled electric foot shocks (100 ms, $2.0 \mathrm{~mA}, 1.0 \mathrm{~Hz}$ ) immediately after stepping down. In post shock trials, the rat was allowed to remain on the platform for $3 \mathrm{~min}$ or, in case it stepped down earlier, to stay on the floor for $1 \mathrm{~min}$.

Testing the pain sensitivity and the stress-induced analgesia (the hot plate test)

The apparatus and the procedure employed in this test were described in detail in our earlier works [19]. The measured variable was the latency $(\mathrm{L})$ of the pawlick response to a thermal $\left(54.5 \pm 0.2^{\circ} \mathrm{C}\right)$ stimulus applied to the paws via the heated floor (hot plate). The testing consisted of 3 trials, a preshock trial (trial 1) and two postshock trials (trial 2 and 3 ). The measured latencies were denoted as L1, L2 and L3, respectively. Each trial consisted in placing the rat on the hot plate where it remained until the expected response, i.e. licking the hind foot, or until $60 \mathrm{~s}$ elapsed. Immediately after trial 1 , the rat was transferred to the shock chamber where it received electric foot shocks (100 ms, $2.0 \mathrm{~mA})$, one every $2 \mathrm{~s}$, for $2 \mathrm{~min}$. Trial 2 was performed several seconds after the shocking. Trial 3 was performed $24 \mathrm{~h}$ after trial 2. In this test the paw-lick latency in trial 1 (L1) is regarded as a measure of the pain sensitivity. The L2/L1 ratio is regarded as a measure of the stress-induced analgesia and provides some information about the magnitude of the shock-induced stress response. The L3/L1 ratio allows for making some inferences about the strength of the association between the test environment and the aversive stimuli (heat and foot shocks). In other words, it provides some clues concerning the memory function $[20,21]$.

Startle reflex (SR) and prepulse startle reflex inhibition (PPI)

The apparatus was a four-unit Startle Response System (TSE GmbH, Germany). All units could be simultaneously controlled by the computer software. The startle reflex (SR) - a body flinch — was evoked by a SR inducing stimulus (SRiS) which was a $20 \mathrm{~ms}$ burst of $115 \mathrm{~dB}$ white noise. The SR amplitude (in grams) was automatically measured and the score stored in the computer memory. SR prepulse inhibition (PPI), i.e. reduction of the SR amplitude contingent upon the occurrence of a short sensory stimulus before the SRiS, was tested by presenting an auditory stimulus (a 20 ms click - prepulse (PP) - of 70,75 or $80 \mathrm{~dB}$ intensity and duration of $20 \mathrm{~ms}$ ). PP started $100 \mathrm{~ms}$ before the SRiS. The measured variable was the SR amplitude. On the first day the rats were adapted to the test environment by placing them into the startle cabinets for $10 \mathrm{~min}$. The basic test was performed in the next two days and consisted of two steps: Step 1 - testing the short-term habituation, and Step 2 - PPI testing. Step 1 and 2 were about $23 \mathrm{~h}$ apart. In Step 1, the rat was placed into the startle cabinet and left undisturbed for about $3 \mathrm{~min}$. Then it was presented with five series of SRiS, ten SRiS in one series, at $1 \mathrm{~min}$ between series intervals. The intervals between successive SRiS in the series varied randomly from 20 to $60 \mathrm{~s}$.

The testing in Step 2 consisted of three blocks of stimulus presentations (trials) with 2-3 min intervals between blocks. Block 1 and 3 consisted of ten trials each, and in each trial the SRiS was presented alone. Block 2 consisted of 40 trials. In ten trials of block 2 the SRiS was presented alone, and in 30 it was preceded by $\mathrm{PP}$ of $70 \mathrm{~dB}, 75 \mathrm{~dB}$ or $80 \mathrm{~dB}$ (ten trials for each PP intensity). The trials were distributed randomly within the block. The intertrial interval varied randomly from 20 to $60 \mathrm{~s}$. PPI was calculated in percent from the proportion of the mean SR amplitude in trials with PP of a given intensity and the mean SR amplitude in trials without PP in block 2. Comparison of the data from block 1 and 3 supplied information about the stability of SR in Step 2. 
Testing the sensorimotor coordination - the rotarod test The apparatus was a home-made, four-unit rotarod. It consisted of a $50 \times 50 \times 50 \mathrm{~cm}$ cage with translucent front door. The cage was separated by perpendicular walls into four equal compartments each equipped with a grid metal floor connected to a constant current shock generator. A wooden rod, $8.0 \mathrm{~cm}$ in diameter, driven with an electric motor, was mounted $18 \mathrm{~cm}$ above the floor. The testing consisted of two trials $24 \mathrm{~h}$ apart. In the first trial the rat was placed on the wooden rod rotating at a constant speed of $7.0 \mathrm{rpm}$. After falling down onto the electrified floor it received a foot shock $(2.5 \mathrm{~mA}, 100 \mathrm{~ms}$, at $0.3 \mathrm{~Hz}$ ) during $10 \mathrm{~s}$. Immediately after the foot shock, the rat was returned to its home cage. On the next day it was retested in the same way as on the first day but without the foot shock. The measured variable was the latency of falling off the rod onto the floor.

\section{Statistics}

In most cases a two-way ANOVA (groups x measurements) for repeated measures was employed for statistical assessment of the differences. When a significant interaction was found, it was followed by one-way ANOVA and Tukey's test for pairwise comparisons. In some instances nonparametric one-way ANOVA (Kruskal-Wallis test) was used. It was preceded by Bartlett test to assess the homogeneity of variances. Pairwise comparisons were performed with the Sheffe test. Differences were regarded as significant when the probability of the null hypothesis was $5 \%$ or less.

\section{RESULTS}

\section{Experiment 1. Effects of perinatal MeHg exposure}

Observations made before weaning

In pups of the high dose group the body weight increased at a lower rate than in controls and the timing of some developmental milestones was disturbed (incisor eruption was hastened). Moreover, these rats, males and females, showed slower progress in the free fall righting and forepaw suspension test performances. The only significant difference found in pups of the low exposure group concerned the negative geotaxis; these pups, males and females, performed better than pups of the control group [14].

Neurobehavioural functions in adulthood General health status of the progeny after adolescence Eighty rats participated in this part of the study. There were 14 females and 15 males born to mothers of the control group, 15 females and 14 males born to mothers of the low exposure group ( $\mathrm{MeHg} 0.5 \mathrm{mg} / \mathrm{kg} / \mathrm{day}$ ), and 11 females and 11 males born to mothers of the high dose group (MeHg $2.0 \mathrm{mg} / \mathrm{kg} / \mathrm{day}$ ). At the age of three months the groups, males and females, did not differ significantly in general appearance, home cage behaviour and body weight.

\section{Open field test: testing spontaneous locomotor activity}

In females, in both exposed groups, the number of ambulation episodes was smaller and, in the low dose group, the walked distance was significantly shorter than in females of the control group. In males there were no differences between groups (Fig. 1). No differences between exposure groups, males or females, were found in the number of rearings (exploratory activity) (data not shown).

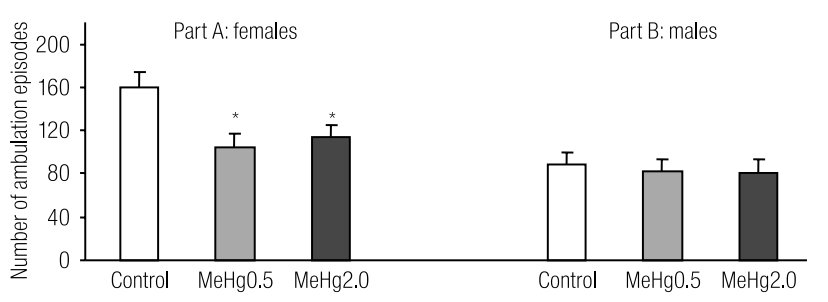

The bars represent group means and S.E. of the number of ambulation episodes during $1 \mathrm{~h}$ stay in the open field. Statistics (Kruskal-Wallis one-way ANOVA):

Females: $\mathrm{X}^{2}=8.365, \mathrm{p}<0.01$.

Males: $\mathrm{X}^{2}=0.144, \mathrm{p}=0.866$.

$* \mathrm{p}<0.05$ compared to control.

Fig. 1. Behavioural effects of perinatal $\mathrm{MeHg}$ exposure. Spontaneous motoric activity (open field test) in adult progeny of unexposed mothers (control) and mothers receiving $\mathrm{MeHg}$ at $0.5 \mathrm{mg} / \mathrm{kg} / \mathrm{day}(\mathrm{MeHg} 0.5$ ) or $2.0 \mathrm{mg} / \mathrm{kg} / \mathrm{day}(\mathrm{MeHg} 2.0)$ during gestation and lactation. 

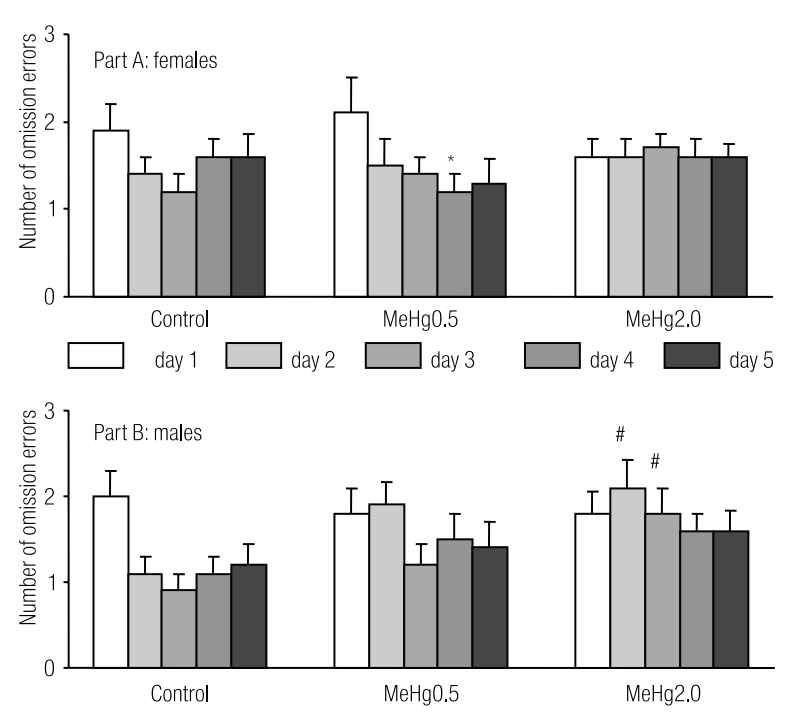

The bars denote the number of omission errors (means and S.E.) in successive days of training in females (A) and males (B).

${ }^{*} \mathrm{p}<0.05$ compared to day 1 in the same group.

$\# \mathrm{p}<0.05$ compared to same days in control group.

Statistics (two-way ANOVA).

Females:

Measurement effect: $\mathrm{F}(1.37)=2.27, \mathrm{p}=0.14$.

Group effect: $F(2.37)=0.24, p=0.79$.

Interaction: $\mathrm{F}(2.37)=3.79, \mathrm{p}<0.05$.

Males:

Measurement effect: $\mathrm{F}(1.37)=4.21, \mathrm{p}=0.05$.

Group effect: $F(2.37)=3.68, \mathrm{p}<0.05$.

Interaction: $\mathrm{F}(2.37)=5.21, \mathrm{p}=0.01$.

Fig. 2. Behavioural effects of perinatal MeHg exposure. Radial maze performance in the progeny of rat mothers of the control group (Control), and groups exposed to $\mathrm{MeHg}$ during gestation and lactation at $0.5 \mathrm{mg} / \mathrm{kg} /$ day $(\mathrm{MeHg} 0.5)$ or $2.0 \mathrm{mg} / \mathrm{kg} /$ day (MeHg 2.0).

\section{Radial maze test: testing short-term spatial memory}

In males as well as females, no differences between groups in the number of omission errors were found during successive days of adaptation (data not shown). During training, males of the high dose group made significantly more omission errors than males of the control group (Fig. 2). No significant differences between groups (males and females) were found in the number of perseveration errors and trial duration (data not shown).

Passive avoidance performance: testing long-term memory In the shock trial, the step-down latency was similar in all groups (15-20 s). In successive post shock trials the latency was markedly increased. In females there were no

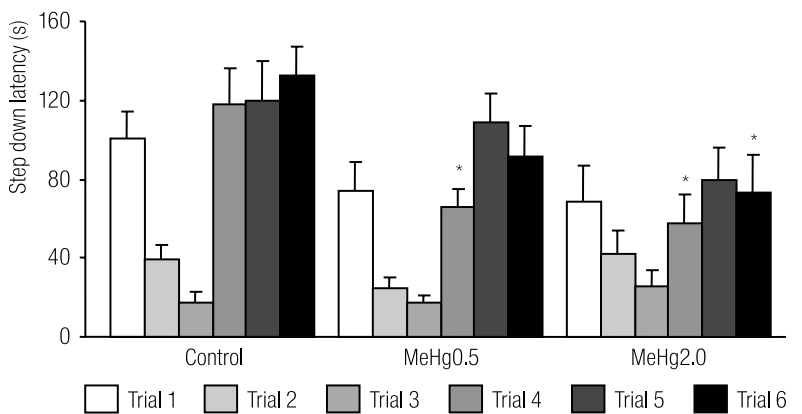

$* p<0.01$ compared to the same trial in control group.

The bars represent mean step down latencies in successive trials of the test in groups of males.

Trial 1, 2, 3 and 4 were performed at $24 \mathrm{~h}$ intervals.

Trial 5 and 6 were performed 3 days and 6 days after the shock trial (trial 3), respectively.

Statistics (two-way ANOVA):

Measurement effect: $\mathrm{F}(1.37)=27.9, \mathrm{p}<0.001$.

Group effect: $\mathrm{F}(2.37)=2.93, \mathrm{p}=0.07$. Interaction: $\mathrm{F}(2.37)=7.89$. $\mathrm{p}<0.001$.

Fig. 3. Behavioural effects of perinatal MeHg exposure. Passive avoidance performance in the progeny of rat mothers of the control group (control), and groups exposed to $\mathrm{MeHg}$ during gestation and lactation at $0.5 \mathrm{mg} / \mathrm{kg} / \mathrm{day}(\mathrm{MeHg} 0.5)$ or $2.0 \mathrm{mg} / \mathrm{kg} /$ day ( $\mathrm{MeHg} 2.0$ ).

differences between groups in post shock trials (data not shown). In males, however, in both exposed groups in the first post shock trial and in the last post shock trial in the high dose group, the latencies were significantly shorter than in the control group (Fig. 3). It suggests that both groups were impaired, but in the high dose groups the impairment was more evident.

\section{Hot plate test: assessment of pain sensitivity and the stress- induced analgesia}

A comparison of the direct L1, L2 and L3 values revealed no significant differences between groups in the female population. In males, however, in the high-exposure group, the $\mathrm{L} 3$ value as well as the $\mathrm{L} 3 / \mathrm{L} 1$ ratio were significantly smaller than in the control group (Fig. 4).

\section{Startle response (SR) and startle prepulse inhibition (PPI)}

After a very close examination of the raw data, it appeared that some records contained a substantial proportion of artefacts. Therefore, the results of SR and PPI testing in Experiment 1 have been excluded. 


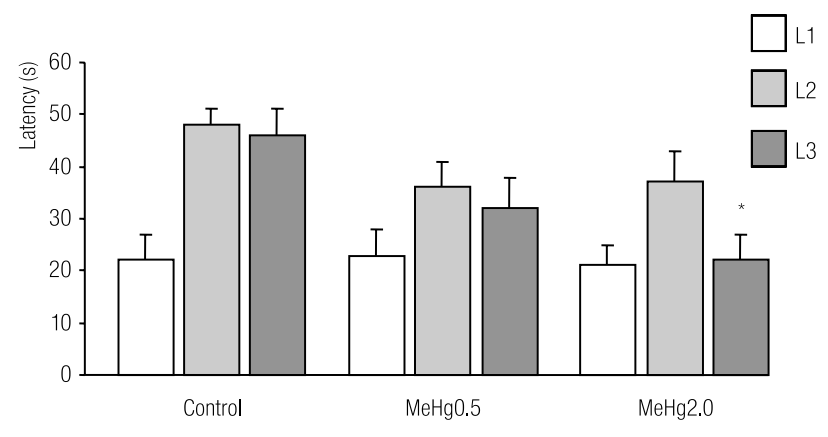

${ }^{*} p<0.05$ compared to corresponding trial in the control group.

The bars represent latencies (means and S.E.) of the paw-lick response to a painful thermal stimulus $\left(54.5^{\circ} \mathrm{C}\right)$ before (L1), immediately after (L2) and $24 \mathrm{~h}$ after (L3) a 2 min series of footshocks in males.

Statistics (two-way ANOVA):

Measurement effect: $\mathrm{F}(1.37)=25.49, \mathrm{p}<0.001$.

Group effect: $F(2.37)=1.81, p=0.18$.

Interaction: $\mathrm{F}(2.37)=14.49, \mathrm{p}<0.001$.

Fig. 4. Behavioural effects of prenatal MeHg exposure: Hot plate test performance in the male progeny of rat mothers of the control group (Control), and groups exposed to $\mathrm{MeHg}$ during gestation and lactation at $0.5 \mathrm{mg} / \mathrm{kg} / \mathrm{day}(\mathrm{MeHg} 0.5)$ or $2.0 \mathrm{mg} / \mathrm{kg} /$ day $(\mathrm{MeHg} 2.0$ ).

\section{Summary of the effects of perinatal MeHg exposure}

The results obtained in this part of the study indicate:

- reduced locomotor activity in female progeny of both exposed groups (lower scores in the open field test);

- increased number of omission errors (distractibility) but not perseveration errors (memory) in males of the high dose group;

- impaired passive avoidance performance in male progeny of the high and low dose group (in the low dose group this effect was less pronounced);

- faster recovery from the effects of stressful experience or impaired memory (hot plate test): effect present in male progeny of both exposure groups but it was statistically significant only in the high dose group.

\section{Experiment II. Effects of the perinatal PCB 153 exposure} Observations made before weaning

Statistically significant and reliable differences were noted in case of two measurements only: body weight gain and grip release latency in the forepaw suspension test. Pups of the high dose group gained weight faster than pups of respective control groups. This effect was notable in both genders but in males it was less pronounced. In the forepaw suspension test, males, mainly of the high dose group, released the paw grip significantly sooner than males of the control group [14].

Neurobehavioural functions in adulthood

General health status of the progeny after adolescence

The animals used in this part were 14 males and 12 females born to mothers of the control group, 14 males and 14 females born to mothers of the low $(1.0 \mathrm{mg} / \mathrm{kg} /$ day $)$ exposure group, and 12 males and 14 females born to mothers of the high $(5.0 \mathrm{mg} / \mathrm{kg} / \mathrm{day})$ exposure group. At the age of three months the groups did not differ in general appearance, home cage behaviour or body weight (data not shown).

\section{Open field test: testing spontaneous locomotor activity}

In females of both exposed groups, the locomotor activity in the open field - the number of ambulation movements in both groups, and the walked distance in the high dose group - was significantly increased compared to females of the control group (Fig. 5). In males no significant differences between groups were found (data not shown).

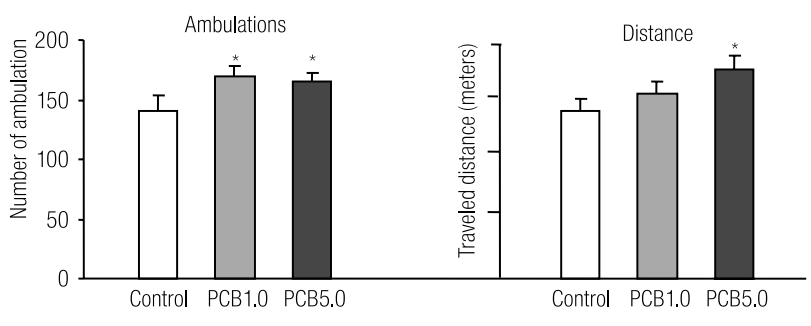

$* \mathrm{p}<0.05$ compared to control.

Diagrams to the left and to the right refer to the number of ambulations and the traveled distance, respectively, during 1 hour measurement.

Bars represent means and S.E.

Fig. 5. Behavioural effects of perinatal PCB 153 exposure. Locomotor activity in adult female progeny of rat mothers of the control group (control) and groups exposed to PCB 153 during gestation and lactation at daily doses of $1.0 \mathrm{mg} / \mathrm{kg} / \mathrm{day}$ (PCB 1.0) or $5.0 \mathrm{mg} / \mathrm{kg} / \mathrm{day}$ (PCB 5.0). 


\section{Radial maze test: testing short-term spatial memory}

Either during the adaptation or during the training phase of the test, reliable significant differences between groups, males or females, were not found in the number of omission errors or perseveration errors (data not shown).

\section{Passive avoidance performance: testing long-term memory}

In all postshock trials the exposed groups, males or females, did not differ significantly from respective control groups in the latency of the step-down response (data not shown).
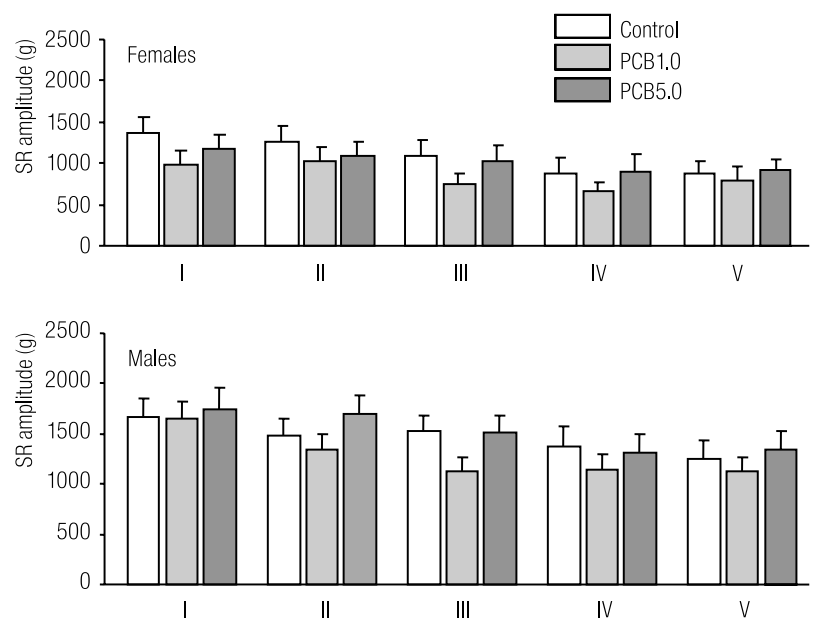

The bars represent group means and S.E. of the SR amplitude (in grams) in successive five blocks of the stimulus presentations. Roman numerals $(\mathrm{X}$ axis $)-$ successive blocks. Each block $=10$ SRs. Between-stimulus interval within each block $=20-60 \mathrm{~s}$.

Between-block interval $=1 \mathrm{~min}$.

Statistics (two-way ANOVA):

Females:

Measurement effect: $\mathrm{F}(1.39)=13.38, \mathrm{p}=0.001$.

Group effect: $F(2.39)=0.81, p=0.45$.

Interaction: $\mathrm{F}(2.39)=4.38, \mathrm{p}=0.02$.

Males:

Measurement effect: $F(1.39)=16.53, p<0.001$.

Group effect: $\mathrm{F}(2.39)=0.64, \mathrm{p}=0.53$.

Interaction: $\mathrm{F}(2.39)=5.0, \mathrm{p}=0.01$.

Fig. 6. Behavioural effects of prenatal PCB 153 exposure in adult offspring: Short-term habituation of the auditory startle response (SR) in the male and female progeny of the control group (control), and groups exposed to PCB 153 during gestation and lactation at $1.0 \mathrm{mg} / \mathrm{kg} / \mathrm{day}$ (PCB 1.0) or $5.0 \mathrm{mg} / \mathrm{kg} / \mathrm{day}$ (PCB 5.0). SR was induced by white noise bursts (20 ms, $115 \mathrm{~dB})$.

\section{Hot plate test - assessment of pain sensitivity and} the stress-induced analgesia

Either in the female or the male progeny the groups did not differ significantly in the direct L1, L2 and L3 values as well as the $\mathrm{L} 2 / \mathrm{L} 1$ or $\mathrm{L} 3 / \mathrm{L} 1$ ratios (data not shown).

\section{Startle response (SR) and startle prepulse inhibition (PPI)}

SR short-time habituation: During the habituation phase of the test, the SR amplitude decreased gradually across successive blocks of SRiS presentations. In the female and in the male progeny of the low dose group the SR amplitudes were notably lower. Moreover, in males (and in females) of this group the SR amplitudes decreased faster
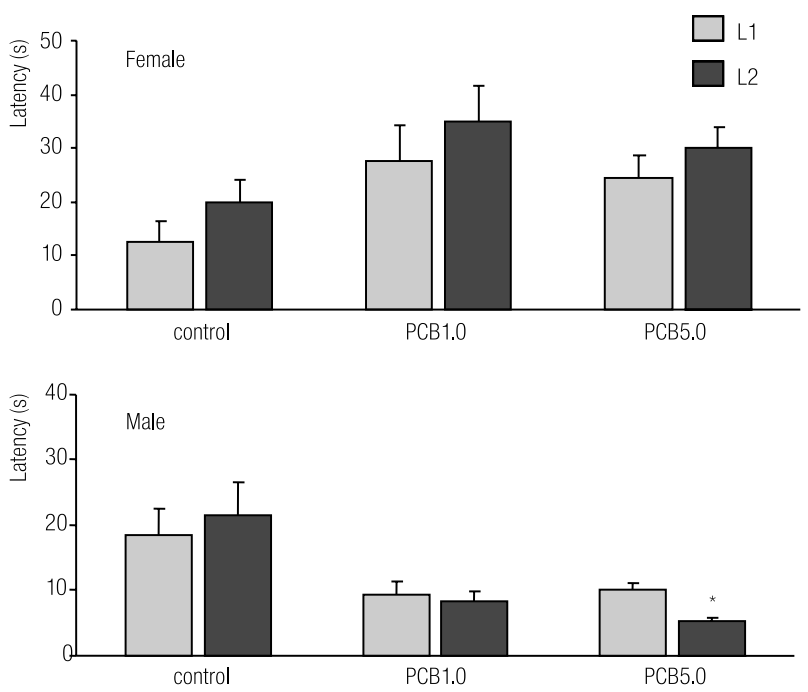

$* p<0.05$ compared to corresponding trial in the control group. The bars represent latencies in sec (means and S.E) of falling off the rotating rod in two trials performed $24 \mathrm{~h}$ apart. In the first trial the falling off was punished by footshock.

The upper and the lower parts of the diagram refer to females and males, respectively.

Statistics (two-way ANOVA):

Females:

Measurement effect: $F(1.39)=3.20, p<0.1$.

Group effect: $F(2.39)=1.35, p=0.2$.

Interaction: $\mathrm{F}(2.39)=0.19, \mathrm{p}=0.83$.

Males:

Measurement effect: $\mathrm{F}(1.39)=0.88, \mathrm{p}=0.35$.

Group effect: $F(2.39)=3.92, p<0.05$.

Interaction: $\mathrm{F}(2.39)=5.41, \mathrm{p}<0.01$.

Fig. 7. Behavioural effects of prenatal PCB 153 exposure.

Rotarod test performance in the progeny of the control group and groups exposed to PCB 153 during gestation and lactation at $1.0 \mathrm{mg} / \mathrm{kg} /$ day (PCB 1.0) or $5.0 \mathrm{mg} / \mathrm{kg} /$ day (PCB 5.0 ). 
in successive blocks (significant group x block interaction) (Fig. 6).

PPI testing: PP presentation before the SRiS resulted in reduction of the SR amplitude and at $80 \mathrm{~dB}$ PP this effect was more pronounced than at $70 \mathrm{~dB}$ PP. Regardless of the PP value, however, the groups within the male as well as female progeny did not differ in the SR amplitude and the level of PPI (data not shown).

\section{Rotarod test - assessment of sensorimotor coordination}

In the female progeny, in both trials of the rotarod test, the differences between groups in the latency of falling off the rotating rod were not significant. In the male progeny, in both trials of the test, animals of both exposed groups performed poorer than animals of the control group. However, the difference appeared significant statistically only for the high dose group (PCB 5.0) and only in the second trial (Fig. 7).

Summary of the effects of perinatal PCB 153 exposure

Testing of the PCB exposed groups indicates:

- increased locomotor open-field activity in the female progeny (effect present in the low and the high dose group);

— signs of facilitated habituation of the startle reflex in males and females of the low dose group;

- impaired rotarod performance in males of the high dose group.

\section{Experiment III. Effects of combined perinatal exposure to MeHg and PCB 153}

Observations made before weaning

Adverse effects of the combined exposure to PCB 153 $(5.0 \mathrm{mg} / \mathrm{kg} /$ day $)$ and $\mathrm{MeHg}(0.5 \mathrm{mg} / \mathrm{kg} /$ day $)$ during gestation and lactation on the maternal health, reproduction success and morphological and physical development of the progeny were not found [14].

Neurobehavioural functions in adulthood

\section{General health status of the progeny after adolescence}

This part of the study was performed on 47 rats. There were 12 females and 11 males born to mothers of the control group and 12 females and 12 males born to mothers exposed to $\mathrm{MeHg}(0.5 \mathrm{mg} / \mathrm{kg} /$ day $)$ and PCB $153(5.0 \mathrm{mg} / \mathrm{kg} /$ day $)$ during gestation and lactation. At the age of three months the groups did not differ in general appearance, home cage behaviour or body weight (data not shown).

\section{Open field test: testing spontaneous locomotor activity}

There were no significant differences between groups in the female and in the male population in the distance travelled during the $1 \mathrm{~h}$ stay in the open field. No differences between groups were also found in the number of ambulation episodes, number of rearings or number of nonambulatory short-distance movements (data not shown).

\section{Radial maze test: testing short-term spatial memory}

During the adaptation stage on day 3 , females of the exposed group made more and males made less arm entries than their counterparts in the control group. Considering the daily variability of this measure, these differences were regarded accidental (data not shown). During the training stage, neither in the female nor in the male progeny significant differences were found between groups in the number of omission errors, perseveration errors and trial duration (data not shown).

\section{Passive avoidance performance: testing long-term memory}

In the female as well as in the male population, significant differences between groups in the step down latency were not found in successive trials of the passive avoidance test (data not shown).

\section{Hot plate test - assessment of pain sensitivity and the stress-induced analgesia}

Neither in the female nor in the male progeny significant differences were detected between groups in the direct L1, $\mathrm{L} 2$ and $\mathrm{L} 3$ values as well as the L2/L1 and L3/L1 ratios (data not shown).

\section{Startle response (SR) and startle prepulse inhibition (PPI)}

SR short-time habituation: In the exposed groups, males or females, the decrease in the SR amplitude across 
successive blocks was more pronounced than in the control groups, but the differences appeared insignificant statistically (data not shown).

PPI testing: Either in the females, or the males, the groups did not differ significantly in the direct SR values regardless of PP magnitude (data not shown).

\section{Rotarod test: - assessment of sensorimotor coordination}

In the rotarod test, there were no significant differences between groups of the female or the male progeny in the time of staying on the rotating rod. The L2 value tended to be higher than the L1 value. However, in none of the groups this difference was significant (data not shown).

Summary of the effects of combined exposure Combinedexposure of rat mothersto $\mathrm{MeHg}(0.5 \mathrm{mg} / \mathrm{kg} / \mathrm{day})$ and PCB $153(5.0 \mathrm{mg} / \mathrm{kg} /$ day $)$ during pregnancy and lactation results in no overt neurobehavioural alterations in their adult offspring.

\section{DISCUSION}

\section{Effects of exposure to $\mathrm{MeHg}$}

The results of Experiment I (MeHg exposure) indicate that: i) both exposure levels used in the present study were effective in inducing behavioural alterations in adult progeny, ii) alterations found in females differed qualitatively from alterations found in males. Effects observed in females (reduced locomotor activity in the open field) suggest a lowered general arousal (or increased fearfulness). Effects seen in males (deficient passive avoidance and reduced paw-lick latency in the hot-plate test) suggest a deficit in long-term memory.

Regarding the effectiveness of the $\mathrm{MeHg}$ dosing levels, it is worth noting that in females of the low dose group the reduction of the locomotor activity was more pronounced than in females of the high dose group. In case of the alterations found in males - the deficits in the passive avoidance and hot plate behaviour - the dose-effect, relationship is as it might be expected: in males of the high dose group the deficits are more evident than in males of the low dose group. We will come back to the issue of the dose-effect relationship at the end of the discussion section.

What regards the type of the discovered alterations, they are only to some extent consistent with those reported by other authors. In case of the open field test, the direction of the change found in the present study, i.e. a reduction of locomotor activity, is the same as that observed by other authors. Inconsistency concerns the gender relationship. According to some reports, perinatal $\mathrm{MeHg}$ exposure in rats results in reduced locomotor activity in males [22]. In mice, however, females are the affected gender [23]. In all the remaining tests of Experiment I, effects were found in males only, which is consistent with observations of other authors suggesting a higher vulnerability of male fetuses to the $\mathrm{MeHg}$ toxic action [24]. From the review paper by Castoldi et al. [22], as well from the recent report by Ferraro et al. [25] it appears that passive avoidance is the test situation in which the deficits produced by perinatal/prenatal $\mathrm{MeHg}$ exposure are commonly reported. Notably, deficits in passive avoidance were produced by a single high-dose $\mathrm{MeHg}$ administration as well by repeated low level exposures. Thus, the fact that this effect was noted in the present study adds credibility to the results of the remaining tests. The results of the hot-plate test provide additional confirmation of the passive avoidance deficit. The longer L3 in this test seems to be related more to the memory of the fact that paw licking is followed by punishment than to stress-related analgesia [25]. In other words, the L3 provides the same information as the step-down latency in the passive avoidance test.

The effects found during testing in the radial maze - increased number of omission errors, but not perseveration errors in males of the high dose group - suggest an increased distractibility but intact spatial working memory. The published reports concerning the influence of perinatal $\mathrm{MeHg}$ exposure on spatial memory are not univocal; reported were negative as well as positive effects [21]. Therefore, there is no ground for questioning the observation made in the present work. 


\section{Effects of exposure to PCB 153}

The results of Experiment II indicate that both exposure levels resulted in neurobehavioural alterations in adult progeny, while some of the alterations - increased locomotion in the open field - were present only in females, and some - poor rotarod performance - only in males. The effect found in females suggests an increased behavioural arousal, and that found in males indicates a deficit in sensorimotor coordination.

The effects of a perinatal PCB exposure on motoric functions have been described in several reports. However, the variability of test designs, results obtained, PCB congeners tested, and exposure regimes do not allow for drawing valid conclusions [27]. No reports were found concerning the effects of perinatal exposure to PCB 153 on the open field activity. Two reports describe operant behaviour of adult rats exposed to PCB 153 with mother's milk. An increased motoric activity, suggesting an inability to refrain from performance of a learned movement (pressing a bar) was observed in the male but not in the female progeny $[28,29]$. Similar effects were described after a perinatal exposure to a PCB mixture [30].

The effect found in males in Experiment 2 of the present study suggests either a reduced muscular strength or impaired sensorimotor coordination. Other authors observed similar effects after a perinatal exposure to Aroclor 1254 $[12,27]$. It is worth noting that, during the preweaning period of life, males of the exposed groups (particularly of the high dose group) were deficient in the forepaw suspension test (showed reduced grip strength) [14]. It would not be reasonable to exclude then, that the poor rotarod performance in adulthood was due to a persistence of the deficits present in the preweaning period of life. According to some authors, the main functional domains affected by a perinatal exposure to ortho substituted (noncoplanar) PCBs (like PCB 153) are learning and memory, especially if spatial discrimination is required [31,32]. From the studies by Hussain et al. [32,33,34] it appears that perinatal exposure to PCB 153, as well as other PCBs, results in an impairment of the long-term potentiation (LTP) in the hippocampus. Such an effect indicates a reduced ability for plastic changes in the hippocampus and the resultant impaired ability to solve tasks requiring functional integrity of this structure. Such tasks are passive avoidance and radial maze. However, in the accessible literature we found no reports dealing with the effects of perinatal exposure to PCB 153 on the performance in these tasks in adulthood. Therefore, we do not know whether the absence - in Experiment II — of differences between groups in performance in these two tasks was due to a too low dosing level or to other variables. (It is worth noting here that according to Hussain et al. [32] $1.25 \mathrm{mg} / \mathrm{kg}$ of PCB 153 per day from GD3 to PND 21 suffices to reduce markedly the ability to generate LTP in the hippocampus).

\section{Effects of combined PCB 153 and MeHg exposure}

A comparison of the effects of separate exposures allows one to expect that if MeHg and PCB 153 interacted synergistically, or additively, then the profile of effects produced by the combined exposure might be as follows: no differences between groups in the results of the open field test as well as the remaining tests in females but differences in the results of the passive avoidance, hot plate and rotarod tests in males. Differences were not observed in Experiment 3 either between female or male groups, which suggests an antagonistic type of MeHg and PCB 153 interaction in the present study. The same conclusion has been drawn from the observations concerning the effects detected during the preweaning period of life [14] as well as those concerning the effects of the exposures on the propensity to sensitisation by amphetamine [16] and brain catecholamine concentration [17]. Antagonistic type of interaction has also been suggested by results obtained in studies on discrimination learning and glutamatergic transmission in adult rats exposed perinatally to PCB 153 and $\mathrm{MeHg}$ [35] and neurobehavioural studies of Sugawara et al. [36]. Only two study reports presented results suggesting synergism or additivity. In one study, mice were exposed to MeHg and PCB 153 only once at PND 10. In maturity, in animals exposed to both these neurotoxicants, habituation of the locomotor activity was impaired more severely than in animals exposed to $\mathrm{MeHg}$ or PCB alone [37]. In the second study on rats, a combined perinatal exposure to $\mathrm{MeHg}$ and Aroclor 1254 resulted in a stronger 
impairment of the rotarod behaviour than did separate exposures [12]. $\mathrm{MeHg} / \mathrm{PCB}$ interaction was not found in studies using catecholaminergic transmission [38], cholinergic (muscarinic) receptor density [39,40], or spatial alternation [41] as endpoints.

Experimental proofs for both synergistic or antagonistic $\mathrm{MeHg} / \mathrm{PCB}$ interaction have been provided also by results of the in vitro studies. Apart from the Bemis and Seegal studies [2,3] already quoted, evidence of an additive or weakly synergistic interaction has been found by Johansson et al. [42] in studies on AtT20 pituitary cell line using cell viability as the endpoint. Notably, the interaction was evident only when each of the toxicants (MeHg, PCB 126 or PCB 153) was present in the medium at concentration proved effective in conditions of separate exposure $(\geq 1.0 \mu \mathrm{M}$ in case of $\mathrm{MeHg}$ and 25 or $50 \mu \mathrm{M}$ in case of PCB 126 or 153, respectively). In all the remaining in vitro studies, the type of interaction was concentration dependent. In the Bemis and Seegal studies [2,3] on the cerebellar granule cells and $\mathrm{Ca}_{2}+$ release as the endpoint, $\mathrm{MeHg}$ interacted synergistically with the PCB when the concentration was low and exposure time short. High concentrations or long exposure times resulted in antagonism [3]. In studies performed by Vettori et al. [43] on PC12 cell lines and cell viability as the endpoint, antagonism was observed at low concentrations of the toxicants (MeHg and PCB 153) and additivity was noted when the concentrations were high. Very interesting results have been obtained by the same authors in an "asynchronous" experiment [44]. Antagonistic interaction was observed when the cells were preexposed to $\mathrm{MeHg}$ alone before adding the PCB (PCB 153) to the medium. Interestingly, this antagonism was most pronounced when $\mathrm{MeHg}$ concentration was ten times lower than the lowest effective concentration in the Johansson et al. study [42]. When cells were preexposed to PCB before adding $\mathrm{MeHg}$, the effect on cells (cell death) suggested additivity or synergism. The authors propose hormesis as one of the possible explanation of the antagonism seen in their study. The hormesis suggested by Goldoni et al. [44] is in fact chemical conditioning hormesis (although the authors did not use this term), a phenomenon in which prior exposure to a chemical toxicant results in reduction of the toxic effect of a subsequent more massive chemical insult $[45,46]$. According to this explanation, preexposure of cells to $\mathrm{MeHg}$ at concentrations too low to kill the cells activates some cellular defence mechanisms that make the cell more resistant to the toxic action of PCB, hence the antagonism. Additivity or synergistic interaction is observed when the cells are pretreated with concentrations sufficiently high to seriously damage or kill the cell. We feel it worth to consider whether the above hypothesis of the MeHgPCB antagonism can be applied for explaining the results obtained in the present study. The Goldoni et al. results suggest that the antagonistic MeHg-PCB interaction is best evident when $\mathrm{MeHg}$ concentration is subtoxic and when $\mathrm{MeHg}$ exposure precedes the exposure to PCB. The MeHg dosing level in Experiment III of the present study $(0.5 \mathrm{mg} / \mathrm{kg} /$ day $)$ could hardly be regarded as toxic. Notably, in other in vivo studies with different endpoints, exposure to $\mathrm{MeHg}$ at this level appeared totally ineffective $[39,40]$. Thus, the condition of low dose (or low concentration) was probably met in the present study. Regarding the second condition, asynchronicity, as the accessible information indicates, the $\mathrm{MeHg}$ transfer from mother to the child occurs mainly through blood [47], whereas PCB is transferred mainly through milk $[48,49]$. It means that, in Experiment 3, during pregnancy the progeny was exposed mainly to $\mathrm{MeHg}$ and mainly to PCB 153 during lactation.

The essence of hormesis is the opposing character of the biological effects produced by low and high doses of a substance: the biphasic (" $\cap$-shaped" or "J-shaped") dose- response curve [50]. If the "hormetic" explanation of the MeHg-PCB antagonism were valid, then one might expect that in conditions of separate exposures the dose response curve for at least one of these neurotoxicants would be " $\cap$-shaped" or "J-shaped". So far, however, reports describing such dose-response relationship for $\mathrm{MeHg}$ or PCB are lacking. The possibility of such a relationship is suggested by some observations from the present as well as the earlier studies. It concerns $\mathrm{MeHg}$ as well as PCB 153. What regards $\mathrm{MeHg}$, during the preweaning 
period of life in the progeny of the low-dose group, development of the negative geotaxis was accelerated, while it was unchanged in the progeny of the high dose group. At adulthood, in females of the low dose group, alterations in the open field behaviour were more pronounced than in females of the high dose group and the propensity for AMPH sensitization was evidently higher in males of the low dose group than in males of the high dose group. What regards PCB, the differences were noted mainly during the preweaning period of life: the pinna detachment and incisor eruption were accelerated in the progeny of the low dose group but delayed in the progeny of the high dose group. It is worth noting that the "J-shaped" doseresponse relationship in case of at least one of the two toxicants could explain why, depending on the exposure level, the observed MeHg-PCB interaction is synergistic or antagonistic. In such a situation, antagonism observed on a behavioural level may be due to additivity or synergism on the molecular level.

To sum up, the results which have been presented in the present and in earlier reports [14,16,17], as well as results obtained by other authors [35,36] indicate that coexposure to $\mathrm{MeHg}$ and PCB 153 during gestation and lactation is not likely to endanger the neurodevelopment of the progeny more than separate exposure to each of these neurotoxicants. to the contrary, the coexposure is even more likely to reduce the risk of some abnormalities compared with separate exposure to those toxicants. This conclusion, however, cannot be generalised; it cannot be excluded (or it is almost certain) that in other conditions (different exposure regime, different concentration combinations, other PCB congeners, and with different experimental endpoints) the results (and the conclusions) would be different. In this situation, synergism or additivity in the $\mathrm{MeHg} / \mathrm{PCB}$ interaction may still be a valid explanation of the inconsistencies between the results obtained on the Faeroe and Seychelles cohorts. Therefore, apart from exact determination of the dose-response relationship(s), future investigations should focus on precise determination of the conditions in which coexposure to $\mathrm{MeHg}$ and PCBs increases, and in which it decreases the risk of adverse developmental effects.

\section{ACKNOWLEDGEMENTS}

This research has been supported by grants from the European Commission (DEVNERTOX Contract no 6PR/03/506143), and the Nofer Institute of Occupational Medicine (IMP-1.19, 20042006). The assistance of Dr. Joanna Piasecka-Zelga in the animal care is greatly appreciated.

\section{REFERENCES}

1. Grandjean P, Landrigan PJ. Developmental neurotoxicity of industrial chemicals. Lancet 2006;368:2167-78.

2. Bemis JC, Seegal RF. Polychlorinated biphenyls and methylmercury act synergistically to reduce rat brain dopamine content in vitro. Environ Health Perspect 1999;107: 879-85.

3. Bemis JC, Seegal RF. Polychlorinated biphenyls and methylmercury alter intracellular calcium concentrations in rat cerebellar granule cells. Neurotoxicology 2000;21:1123-34.

4. Grandjean P, Weihe P, White RF, Debes F, Araki S, Murata $\mathrm{K}$, et al. Cognitive deficit in 7-year-old children with prenatal exposure to methylmercury. Neurotoxicol Teratol 1997;19:417-28.

5. Grandjean P, Weihe P, Burse VW, Needham LL, Storr-Hansen E, Heinzow B, et al. Neurobehavioral deficits associated with PCB in 7-year-old children prenatally exposed to seafood neurotoxicants. Neurotoxicol Teratol 2001;23:305-17.

6. Debes F, Budtz-Jørgensen E, Weihe P, White RF, Grandjean P. Impact of prenatal methylmercury exposure on neurobehavioral function at age 14 years. Neurotoxicol Teratol 2006;28(5):536-47.

7. Davidson PW, Myers GJ, Cox C, Axtell C, Shamlaye C, Sloane-Reeves J, et al. Effects of prenatal and postnatal methylmercury exposure from fish consumption on neurodevelopment at 66 months of age in the Seychelles Child Development Study. JAMA 1998;280(8):701-7.

8. Davidson PW, Myers GJ, Weiss B, Shamlaye CF, Cox C. Prenatal methylmercury exposure from fish consumption and child development: a review of evidence and perspectives from the Seychelles Child Development Study. Neurotoxicology 2006;27:1106-9.

9. Davidson PW, Sloane-Reeves J, Myers GJ, Hansen ON, Huang L-Sh, Georger LA, et al. Association between prenatal exposure to methylmercury and visuospatial ability 
at 10.7 years in the Seychelles Child Development Study. Neurotoxicology 2008;29:453-9.

10. Nakai K, Satoh H. Developmental neurotoxicity following prenatal exposures to methylmercury and PCBs in humans from epidemiological studies. Tohoku J Exp Med 2002;196:89-98.

11. Risher JF, de Rosa C, Murray HE, Jones D. Joint PCBmethylmercury exposures and neurobehavioral outcomes. Hum Ecol Risk Assess 2003;9:1003-10.

12. Roegge CS, Wang VC, Powers BE, Klintsova AY, Villareal S, Greenough WT, Schantz SL. Motor impairment in rats exposed to PCBs and methylmercury during early development. Toxicol Sci 2004;77:315-24.

13. Roegge CS, Morris JR, Villareal S, Wang VC, Powers BE, Klintsova AY, et al. Purkinje cell and cerebellar effects following developmental exposure to PCBs and/or MeHg. Neurotoxicol Teratol 2006;28:74-85.

14. Sitarek K, Gralewicz S. Early developmental effects of separate or combined perinatal exposure to methylmercury $(\mathrm{MeHg})$ and 2,2',4,4,5,5'-hexachlorobiphenyl (PCB 153) in the rat. Int J Occup Med Environ Health 2009;22(2):89-105. DOI 10.2478/v10001-009-0015-6.

15. Longnecker MP, Wolff MS, Gladen BC, Brock JW, Grandjean P, Jacobson JL, et al. Comparison of polychlorinated biphenyl levels across studies of human neurodevelopment. Environ Health Perspect 2003;111:65-70.

16. Lutz P, Wiaderna D, Gralewicz S, Świercz R. Effects of Perinatal MeHg and/or 2,2',4,4',5,5'-hexachlorobiphenyl (PCB153) Exposure on Adult Vulnerability to Amphetamine in the Rat. Polish J Environ Stud 2008;17:557-67. DOI 10.2478/v1001006-0017-6.

17. Świercz R, Grzelińska Z, Majcherek W, Wiaderna D, Lutz P, Sitarek K, et al. Brain catecholamine concentrations in adult rats exposed perinatally to methylmercury and/or PCB153. Polish J Environ Stud 2008;17:587-96.

18. Lutz P, Wiaderna D, Gralewicz S, Kur B. Exposure to chlorphenvinphos, an organophosphate insecticide, prevents from behavioral sensitization to amphetamine. Int J Occup Med Environ Health 2006;19(2):132-41. DOI

19. Gralewicz S, Wiaderna D, Tomas T, Rydzyński K. Behavioral changes following 4-week inhalation exposure to pseudocumene (1,2,4-trimethylbenzene) in the rat. Neurotoxicol Teratol 1997;19:327-33.
20. Boles RC, Fanselow MS. A perceptual-defensive recuperative model of fear and pain. Behav Brain Sci 1980;3:291-301.

21. Fanselow MS. Analgesia as a response to aversive Pavlowian conditional stimuli: Cognitive and emotional mediators. In: Denny MR, editor. Fear, avoidance and phobias. NJ: Erlbaum, 1991,61-86.

22. Castoldi AF, Onishchenko N, Johansson C, Coccini T, Roda E, Vahter M, et al. Neurodevelopmental toxicity of methylmercury: Laboratory animal data and their contribution to human risk assessment. Regul Toxicol Pharmacol 2008;51:215-29.

23. Goulet S, Doré FY, Mirault ME. Neurobehavioral changes in mice chronically exposed to methylmercury during fetal and early postnatal development. Neurotoxicol Teratol 2003;25:335-47.

24. Rossi AD, Ahlbom E, Ogren SO, Nicotera P, Ceccatelli S. Prenatal exposure to methylmercury alters locomotor activity of male but not female rats. Exp Brain Res 1997;117:428-36.

25. Ferraro L, Tomasini MC, Tanganelli S, Mazza R, Coluccia $\mathrm{A}$, Carratù MR, et al. Developmental exposure to methylmercury elicits early cell death in the cerebral cortex and longterm memory deficits in the rat. Int J Dev Neurosci 2008;27: $165-74$.

26. Gower AJ, Tricklebank MD. The effects of cholinergic drugs support an avoidance learning hypothesis of brief footshockinduced analgesia. Neuropharmacology 1986;25:1161-6.

27. Roegge CS, Morris JR, Villareal S, Wang VC, Powers BE, Klintsova AY, et al. Purkinje cell and cerebellar effects following developmental exposure to PCBs and/or MeHg. Neurotoxicol Teratol 2006;28:74-85.

28. Holene E, Nafstad I, Skaare JU, Krogh H, Sagvolden T. Behavioural effects in female rats of postnatal exposure to subtoxic doses of polychlorinated biphenyl congener 153. Acta Paediatr Suppl 1999;88:55-63.

29. Holene E, Nafstad I, Skaare JU, Sagvolden T. Behavioural hyperactivity in rats following postnatal exposure to sub-toxic doses of polychlorinated biphenyl congeners 153 and 126. Behav Brain Res 1998;94:213-24.

30. Sable HJ, Powers BE, Wang VC, Widholm JJ, Schantz SL. Alterations in DRH and DRL performance in rats developmentally exposed to an environmental PCB mixture. Neurotoxicol Teratol 2006;28:548-56. 
31. Newland MCh. Neurobehavioral toxicity of methylmercury and PCBs: effects profiles and sensitive populations. Environ Toxicol Pharmacol 2002;12:119-28.

32. Hussain RJ, Gyori J, DeCaprio AP, Carpenter DO. In vivo and in vitro exposure to $P C B 153$ reduces long-term potentiation. Environ Health Perspect 2000;108(9):827-31.

33. Ozcan M, Yilmaz B, King WM, Carpenter DO. Hippocampal long-term potentiation (LTP) is reduced by a coplanar $P C B$ congener. Neurotoxicology 2004;25(6):981-8.

34. Niemi WD, Audi J, Bush B, Carpenter DO. PCBs reduce long-term potentiation in the CA1 region of rat hippocampus. Exp Neurol 1998;151:26-34.

35. Piedrafita B, Erceg S, Cauli O, Felipo V. Developmental exposure to polychlorinated biphenyls or methylmercury, but not to its combination, impairs the glutamate-nitric oxide-cyclic GMP pathway and learning in 3-month-old rats. Neurosci 2008;154:1408-16.

36. Sugawara N, Ohba T, Nakai K, Kakita A, Nakamura T, Suzuki K, et al. Effects of perinatal coexposure to methylmercury and polychlorinated biphenyls on neurobehavioral development in mice. Arch Toxicol 2008;82(6):387-97.

37. Fischer C, Fredriksson A, Eriksson P. Neonatal co-exposure to low doses of an ortho-PCB (PCB 153) and methyl mercury exacerbate defective developmental neurobehavior in mice. Toxicology 2008;244:157-65.

38. Castoldi AF, Blandini F, Randine G, Samuele A, Manzo L, Coccini T. Brain monoaminergic neurotransmission parameters in weanling rats after perinatal exposure to methylmercury and 2,2',4,4,5,5'-hexachlorobiphenyl (PCB153). Brain Res 2006;1112:91-8.

39. Coccini T, Randine G, Castoldi AF, Grandjean P, Ostendorp G, Heinzow B, et al. Effects of developmental co-exposure to methylmercury and 2,2, 4,4, 5,5'-hexachlorobiphenyl (PCB153) on cholinergic muscarinic receptors in rat brain. Neurotoxicology 2006;27(4):468-77.

40. Coccini T, Roda E, Castoldi AF, Goldoni M, Poli D, Bernocchi G, et al.Perinatal co-exposure to methylmercury and PCB153 or PCB126 in rats alters the cerebral cholinergic muscarinic receptors at weaning and puberty. Toxicology 2007;238:34-48.
41. Widholm JJ, Villareal S, Seegal RF, Schantz SL. Spatial alternation deficits following developmental exposure to Aroclor 1254 and/or methylmercury in rats. Toxicol Sci 2004; 82:577-89.

42. Johansson C, Tofighi R, Tamm Ch, Goldoni M, Mutti A, Ceccatelli S. Cell death mechanisms in AtT20 pituitary cells exposed to polychlorinated biphenyls (PCB 126 and PCB 153) and methylmercury. Toxicol Lett 2006;167:183-90.

43. Vettori MV, Goldoni M, Cagliari A, Poli D, Folesani G, Ceccatelli S, et al. Antagonistic effects of methyl-mercury and PCB153 on PC12 cells after a combined and simultaneous exposure. Food Chem Toxicol 2006;44:1505-12.

44. Goldoni M, Cagliari A, Poli D, Vettori MV, Ceccatelli S, Mutti A. Methylmercury at low doses modulates the toxicity of PCB153 on PC12 neuronal cell line in asynchronous combination experiments. Food Chem Toxicol 2008;46:808-11.

45. Calabrese EJ, Bachmann KA, Bailer AJ, Bolger PM, Borak J, Cai L, et al. Biological stress response terminology: Integrating the concepts of adaptive response and preconditioning stress within a hormetic dose-response framework. Toxicol Appl Pharmacol 2007;222:122-8.

46. Calabrese EJ. Hormesis: why it is important to toxicology and toxicologists. Environ Toxicol Chem 2008;27:1451-74.

47. Sakamoto M, Kakita A, Wakabayashi K, Takahashi H, Nakano A, Akagi H. Evaluation of changes in methylmercury accumulation in the developing rat brain and its effects: a study with consecutive and moderate dose exposure throughout gestation and lactation periods. Brain Res 2002;949:51-9.

48. Lee SK, Ou YC, Yang RS. Comparison of pharmacokinetic interactions and physiologically based pharmacokinetic modeling of PCB 153 and PCB 126 in nonpregnant mice, lactating mice, and suckling pups. Toxicol Sci 2002;65:26-34.

49. Lyche JL, Skaare JU, Larsen HJ, Ropstad E. Levels of PCB 126 and PCB 153 in plasma and tissues in goats exposed during gestation and lactation. Chemosphere 2004;55:621-9. 50. Mattson MP. Hormesis defined. Ageing Res Rev 2008;7:1-7. 